\title{
Estudo do efeito de distintos períodos de fixação em formalina e métodos de recuperação antigênica na técnica de imuno-histoquimica
}

\author{
Study of the effect of different fixation times in formalin and methods of antigen retrieval in \\ immunohistochemistry
}

Maria Teresa de Seixas Alves ${ }^{1}$; Leonor Cristina Manoja Roman²

\begin{abstract}
unitermos
Imuno-histoquímica

Recuperação antigênica

Métodos de fixação

\section{resumo}

Avaliou-se a influência do tempo de fixação em formalina neutra tamponada a $10 \%$ e dos diferentes métodos de resgate de sítio antigênico induzido pelo calor [heat induced epitope retrieval (HIER)] para a imunoexpressão dos anticorpos anti-antígeno nuclear de proliferação celular (PCNA) e anti-AE1AE3 (citoqueratinas), empregados por apresentarem imunocoloração nuclear e citoplasmática ou submembranosa. Foram estudadas cinco tonsilas provenientes de amigdalectomias realizadas no Hospital São Paulo da Escola Paulista de Medicina da Universidade de São Paulo (UNIFESP/EPM), as quais foram seccionadas em $0,5 \mathrm{~cm}^{2}$ cada, fixadas em formalina, por períodos de tempo de seis, 12, 18, 24 e 48 horas e embebidas em parafina. Foram feitos cortes com $4 \mu \mathrm{m}$ em lâminas silanizadas. Para o estudo imuno-histoquímico utilizamos os anticorpos anti-PCNA e AE1AE3, empregando os três métodos de resgate de sítio antigênico: banho-maria, microondas e panela de pressão. A positividade na imunoexpressão do PCNA foi avaliada através da relação núcleos corados/total de núcleos $\times 100$. A intensidade da coloração resultante foi avaliada através da utilização dos programas Corel Photo Paint 9 e UT Morph 2.0. Com relação à recuperação antigênica, concluímos que, para o anticorpo anti-PCNA no material fixado nos períodos de nosso estudo, os melhores resultados foram obtidos com o uso do microondas. O aumento do tempo de fixação interferiu na queda da imunopositividade do PCNA, em especial após o período de 24 horas. Em relação ao parâmetro intensidade de coloração para AE1AE3 nenhum dos métodos foi superior. A metodologia estudada para a análise semiquantitativa na intensidade da reação coincidiu com os resultados obtidos na avaliação criteriosa de cada uma das lâminas.
\end{abstract}

\section{abstract}

The effects of fixation time in buffered formaline at $10 \%$ on different methods of antigenic site retrieval induced by heat (HIER) for the detection of the expression of antibodies anti-PCNA (nuclear proliferation antigen) and anti-AE1 and AE3 (citokeratins) were studied. Specimens with cross section of $0,5 \mathrm{~cm}^{2}$ from five Tonsils from ellective tonsillectomies done at Hospital São Paulo UNIFESP/EPM were fixed for six, 12, 18, 24 and 48 hours and embedded in paraffin for the production of $4 \mu \mathrm{m}$ sections. For HIER was used a steamer, microwave oven and pressure cooker. The level of PCNA expression was assessed by the ratio stained nuclei: total number of nuclei. The staining intensity was assessed by using Corel Photo Paint 9 and UT Morph 2.0 softwares. The present study has shown that: 1) for the detection of anti-PCNA, the use of a microwave oven provided the best results; 2) for the detection of anti-PCNA, longer fixation periods, specially after 24 hours, causes the staining intensity to decrease; 3) for the detection of AE1 and AE3, all procedures used provided equivalent levels of staining. key words Imunohistochemistry

Antigen retrieval

Fixation methods

1. Médica patologista; docente do Departamento de Patologia e doutora em Patologia/Escola Paulista de Medicina da Universidade Federal de São Paulo (EPM/UNIFESP), Brasil. 


\section{Introdução}

A primeira reação de imuno-histoquímica foi realizada há cerca de meio século ${ }^{(2)}$, quando foi introduzida a técnica de marcação de anticorpos com produtos fluorescentes, tais como o isocianato de fluoresceína, para a detecção de antígenos teciduais.

A seguir, Nakane e Pierce ${ }^{(16)}$ substituem o isocianato de fluoresceína pela enzima peroxidase. Com o desenvolvimento da técnica peroxidase antiperoxidase ${ }^{(23)}$, associada ao método de hibridoma de anticorpo monoclonal ${ }^{(11)}$, houve um grande avanço na área.

Na década de 1980, há um importante incremento no uso da imuno-histoquímica para diagnóstico, em função principalmente do desenvolvimento dos métodos avidinabiotina-peroxidase $(A B C)$ e resgate do sítio antigênico por indução de calor (conhecido como HIER). Esta técnica foi pioneiramente desenvolvida por Shi et al. ${ }^{(20)}$, envolvendo o aquecimento de secções de tecidos em solução tampão de resgate de sítio antigênico ${ }^{(21)}$, em que, através de irradiação de lâminas em forno de microondas imersas em solução de tiocianato de chumbo, foram obtidos excelentes resultados no resgate de sítio de antígenos, para tecidos fixados e embebidos em parafina.

Por causa da toxicidade da última solução, inúmeros outros tampões foram pesquisados, obtendo-se excelentes resultados e sendo hoje amplamente utilizados em imunohistoquímica.

O mecanismo de ação de HIER não é completamente conhecido, seguramente promove uma quebra do crosslink, revertendo a conformação das trocas moleculares na molécula de proteína estabelecidas pelo formol.

Mais recentemente, Shi et al. ${ }^{115,22)}$ investigaram muitos aspectos de HIER e concluíram que o resgate do sítio antigênico está associado à temperatura e ao tempo de aquecimento na solução tampão.O pH da solução é também um importante fator de referência no resgate do sítio antigênico. Sabe-se que alguns anticorpos respondem melhor quando recuperados em $\mathrm{pH}$ mais básico.

Atualmente, as diferentes metodologias de aplicação do calor (HIER) utilizadas variam desde o uso de microondas até panelas de pressão, autoclaves, banho-maria e outros.

A Imuno-histoquimica é uma técnica essencialmente qualitativa, embora aplicações quantitativas possam ser realizadas para determinar a intensidade em que o antígeno se encontra presente na amostra. Seu objetivo básico é a localização topográfica deste na célula ou no tecido.
Análises quantitativas de imunocoloração em secções de tecidos podem ser representadas por produto ou soma da intensidade de coloração e porcentagem da positividade em células e estruturas. Esses dois valores podem ser empregados em variadas fórmulas matemáticas como método de análise quantitativa ${ }^{(14)}$.

A análise da imagem permite a mensuração da intensidade de coloração do método imuno-histoquímico, como o reflexo da concentração do antígeno no tecido.

O grande problema encontrado na tentativa de quantificar a imunoexpressão é representado pelas imprevisíveis alterações na preservação dos espécimes.

\section{Metodologia}

O estudo constou da análise de cinco tonsilas inteiras, provenientes de amigdalectomias realizadas no Hospital São Paulo da Escola Paulista de Medicina da Universidade Federal de São Paulo (EPM/UNIFESP), no período de janeiro a julho de 2002. Após o exame macroscópico, os espécimes foram seccionados em $0,5 \mathrm{~cm}^{2}$ cada e fixados aos pares em formalina neutra tamponada a $10 \%$, por períodos de tempo de seis, 12, 18, 24 e 48 horas. Em seguida, foram embebidos em parafina, dando origem a um total de 25 blocos. Destes, foram confeccionados cortes histológicos com espessura de $4 \mu \mathrm{m}$ em lâminas silanizadas.

As lâminas foram coradas pelo método imuno-histoquímico para os anticorpos monoclonais anti-PCNA (clone PC10, M0879, DAKO Corporation, USA, 1/6000) e anti-AE1AE3 (M3515,DAKO Corporation, USA, 1/200). O método de revelação utilizado foi o LSAB/HRP (K0490, DAKO Corporation, USA, pré-diluído), marcado com a enzima peroxidase.

As lâminas foram lidas com o auxílio de sistema digital de imagem, que consistiu de um microscópio Olympus BX51 com objetivas plan-acromáticas, acoplado a uma câmara da marca Oly 200 e um microcomputador Pentium com $128 \mathrm{mB}$ de memória RAM, com placa digitalizadora de imagens, contendo os softwares Corel Photo Paint 9 e UT Morph versão 2.0 da Universidade do Texas, ambos trabalhando em ambiente Windows.

Para a análise do PCNA foram avaliados dois centros germinativos por lâmina e considerados positivos os núcleos que exibissem algum grau de colorido castanho. A avaliação porcentual da positividade foi feita através da relação núcleos corados/total de núcleos x100. 
Para os dois antígenos pesquisados, a intensidade de coloração foi avaliada, importando-se as imagens digitalizadas para o programa Corel Photo Paint 9, em que foram selecionados e protegidos os tons em castanho através de máscaras. O restante da imagem foi apagada com o uso da ferramenta borracha. As ilustrações estão nas Figuras 1 e 2 .

As imagens resultantes desse processo foram importadas para o programa UT Morph 2.0, sendo realizada a leitura da intensidade da densidade óptica em pixels, que variaram de 0 a 255. Para as lâminas que apresentaram menores intensidades de coloração foram obtidos resultados mais próximos de 255 .

O método estatístico empregado foi o de análise de variância ANOVA e, para se determinar os pares do grupo onde havia diferenças significativas, aplicamos o método de Bonferroni.

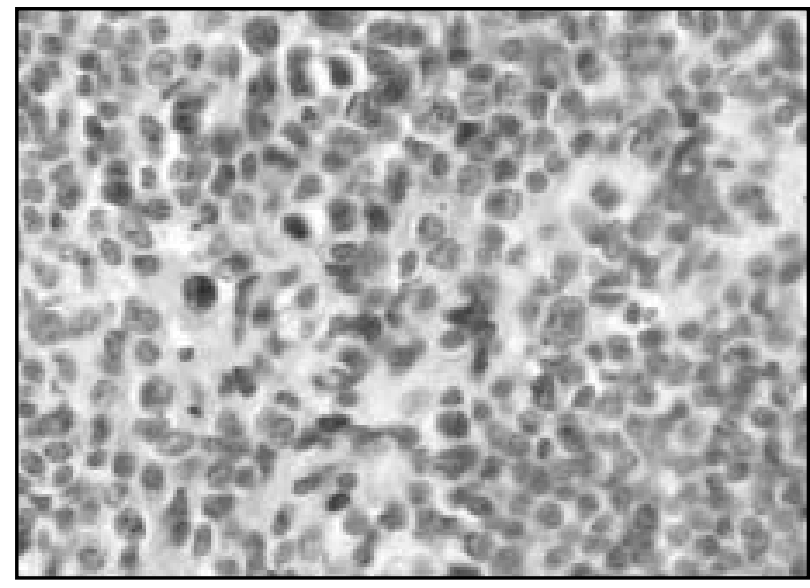

Figura 1 - Fotomicrografia de amígdala humana normal (400X), digitalizada em computador, com 24 horas de fixação em formalina e resgate em microondas. $A$ coloração em castanho é resultante de imunocoloração para o anticorpo anti-PCNA

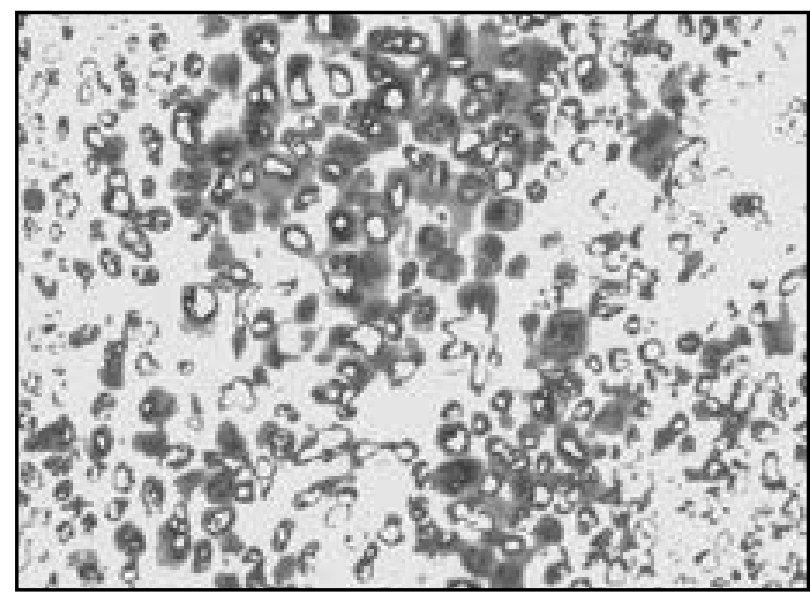

Figura 2 - A mesma amígdala anterior, após ter sido trabalhada pelo programa Corel, onde o colorido que não apresentava qualquer tom em castanho foi eliminado através da ferramenta borracha

\section{Resultados}

Podemos concluir que, pela análise conjunta dos cinco grupos para o PCNA, em relação à intensidade de coloração, os melhores resultados foram obtidos com uso de microondas.

Podemos concluir que o método de resgate é indiferente, quando analisamos a intensidade de coloração do AE1AE3 em relação ao tempo de fixação. Isso confirma os resultados obtidos na análise por grupos, realizada anteriormente.

Ao observarmos tais resultados, concluímos que o tempo de fixação é altamente significante na positividade para o PCNA, havendo queda na imunopositividade em períodos superiores a $24 \mathrm{~h}$ de fixação. Além disso, observamos que o método de recuperação para reverter esses efeitos sobre a positividade é indiferente.

\section{Discussão}

O objetivo principal de nosso estudo consistiu na avaliação das diferentes respostas obtidas na intensidade da imunocoloração, em função das variáveis tempo de fixação e método de recuperação antigênica. Para tanto, empregamos dois antígenos largamente utilizados em nosso laboratório, sendo um de expressão nuclear (anti-PCNA) e outro citoplasmático ou submembranoso (anti-AE1AE3).

Alguns estudos apontam melhores resultados no resgate do sítio antigênico através do uso de tampão citrato de sódio pH 6 para antígenos de expressão citoplasmática ${ }^{(6,25,27)}$, e tampão glicina EDTA pH 3,6 para os de expressão nuclear ${ }^{(10)}$.

Em nosso trabalho, optamos pelo emprego do tampão citrato de sódio $\mathrm{pH} 6$ para ambos os anticorpos, por ser eficaz no resgate de um grande painel de antígenos.

Distintas metodologias de resgate de sítio antigênico em espécimes fixados em formalina e embebidos em parafina têm sido avaliadas ao longo do tempo, seja através do emprego de pré-digestão enzimática (uso de enzimas proteolíticas), microondas ${ }^{(12,28)}$, panela de pressão(18), banho-maria e outros.

Assim como nos diversos estudos que apontaram melhora significativa na imunocoloração com o uso do microondas em material fixado em formalina e embebido em parafina para grande número de anticorpos ${ }^{(1,4,19)}$, obtivemos de igual modo resultados bastante satisfatórios com a utilização do mesmo em ambos os anticorpos estudados.

Avaliamos em nosso trabalho o anticorpo anti-PCNA (clone PC10) em material fixado em formalina e embebido 
Tabela 1 Intensidade de coloração para o PCNA segundo tempo de fixação e método de resgate

\begin{tabular}{|c|c|c|c|c|c|c|c|}
\hline \multirow{2}{*}{ Método de resgate } & & \multicolumn{6}{|c|}{ Tempo de fixação } \\
\hline & & 6 horas & 12 horas & 18 horas & 24 horas & 48 horas & Total \\
\hline \multirow[t]{5}{*}{ Microondas } & $\mathrm{N}$ & 10 & 10 & 10 & 10 & 10 & 50 \\
\hline & Média & 146,93 & 134,39 & 149,6 & 142,69 & 137,58 & 142,24 \\
\hline & Desvio-padrão & 36,04 & 10,96 & 8,89 & 11,28 & 18,11 & 19,78 \\
\hline & Mínimo & 82,84 & 122,41 & 135,92 & 122,91 & 107,13 & 82,84 \\
\hline & Máximo & 199,98 & 159,54 & 161,6 & 155,79 & 159,93 & 199,98 \\
\hline \multirow[t]{5}{*}{ Panela de pressão } & N & 10 & 10 & 10 & 10 & 10 & 50 \\
\hline & Média & 153,1 & 163,91 & 174,15 & 156,53 & 160,6 & 161,55 \\
\hline & Desvio-padrão & 22,79 & 21,74 & 19,51 & 15,27 & 22,5 & 21,01 \\
\hline & Mínimo & 124,05 & 144,76 & 132,83 & 140,81 & 133,34 & 124,05 \\
\hline & Máximo & 182,87 & 200,66 & 205,61 & 181,4 & 190,88 & 205,61 \\
\hline \multirow[t]{5}{*}{ Banho-maria } & $\mathrm{N}$ & 10 & 10 & 10 & 10 & 10 & 50 \\
\hline & Média & 148,75 & 152,59 & 146,6 & 155,88 & 166,3 & 154,02 \\
\hline & Desvio-padrão & 16,33 & 11,7 & 10,63 & 15,38 & 24,32 & 17,2 \\
\hline & Mínimo & 124,72 & 140,34 & 132,22 & 128,67 & 139,16 & 124,72 \\
\hline & Máximo & 163,94 & 175,93 & 163,49 & 175,11 & 197,51 & 197,51 \\
\hline \multirow[t]{5}{*}{ Total } & N & 40 & 40 & 40 & 40 & 40 & 200 \\
\hline & Média & 145,94 & 143,39 & 153,46 & 148,15 & 149,94 & 148,18 \\
\hline & Desvio-padrão & 23,52 & 20,84 & 17,94 & 17,88 & 23,88 & 21,04 \\
\hline & Mínimo & 82,84 & 114,89 & 132,22 & 100,51 & 107,13 & 82,84 \\
\hline & Máximo & 199,98 & 200,66 & 205,61 & 181,4 & 197,51 & 205,61 \\
\hline
\end{tabular}

Resultado das comparações

Tabela 2 múltiplas para 0 método de resgate

\section{Comparação}

Microondas x p. pressão

Microondas $\mathrm{x}$ banho-maria

P. pressão $\mathrm{x}$ banho-maria

*Estatisticamente significante.

em parafina, com resultados bastante satisfatórios, conforme observado por alguns autores $(7,9)$.

De maneira análoga aos achados da literatura, em que alguns trabalhos relatam queda de imunopositividade para o anticorpo anti-PCNA com aumento do tempo de fixação ${ }^{(8,13)}$, observamos em nosso material a queda no porcentual de núcleos corados no período de tempo de 24 horas de fixação.

Sistemas de análise de imagem para avaliação quantitativa vêm sendo pesquisados ao longo do tempo ${ }^{(17,27)}$, na tentativa de eliminar a subjetividade do sistema semiquantitativo através de cruzes na avaliação da intensidade de imunoexpressão, utilizada hoje por patologistas $(3,8,26)$.

Optamos pela utilização de sistema de análise de imagem para quantificar a imunoexpressão, com base no sistema de quantificação aplicado por Engelman ${ }^{(5)}$ na avaliação do glicogênio hepático.

Assim, concluímos que o método de quantificação empregado mostrou-se de fácil aplicabilidade e reprodutibilidade, com resultados coincidentes com a impressão subjetiva das lâminas pelos pesquisadores. 


\section{Tabela 3 Intensidade de coloração para o AE1AE3 segundo tempo de fixação e método de resgate}

\begin{tabular}{|c|c|c|c|c|c|c|c|}
\hline \multirow{2}{*}{ Método de resgate } & & \multicolumn{6}{|c|}{ Tempo de fixação } \\
\hline & & 6 horas & 12 horas & 18 horas & 24 horas & 48 horas & Total \\
\hline \multirow[t]{5}{*}{ Microondas } & $\mathrm{N}$ & 10 & 10 & 10 & 10 & 10 & 50 \\
\hline & Média & 148,74 & 135,58 & 140,16 & 152,96 & 158,66 & 147,22 \\
\hline & Desvio-padrão & 17,33 & 21,93 & 22,16 & 16,30 & 19,96 & 20,67 \\
\hline & Mínimo & 119,19 & 91,76 & 104,27 & 137,21 & 132,91 & 91,76 \\
\hline & Máximo & 160,49 & 169,76 & 190,42 & 185,41 & 190,42 & 199,98 \\
\hline \multirow[t]{5}{*}{ Panela de pressão } & $\mathrm{N}$ & 10 & 10 & 10 & 10 & 10 & 50 \\
\hline & Média & 158 & 166,22 & 155,19 & 141,91 & 159,38 & 156,14 \\
\hline & Desvio-padrão & 29,91 & 12,6 & 17,41 & 25,55 & 17,9 & 22,2 \\
\hline & Mínimo & 126,34 & 146,91 & 124,76 & 92,79 & 129,37 & 92,79 \\
\hline & Máximo & 197,54 & 194,25 & 176,72 & 165,64 & 186,26 & 197,54 \\
\hline \multirow[t]{5}{*}{ Banho-maria } & $\mathrm{N}$ & 10 & 10 & 10 & 10 & 10 & 50 \\
\hline & Média & 142,79 & 152,11 & 157,4 & 153,28 & 152,44 & 151,6 \\
\hline & Desvio-padrão & 27,49 & 12,34 & 21,85 & 21,47 & 24,77 & 21,8 \\
\hline & Mínimo & 90,38 & 133,18 & 118,56 & 133,09 & 109 & 90,38 \\
\hline & Máximo & 166,47 & 173,03 & 191,06 & 202,48 & 198,94 & 202,48 \\
\hline \multirow[t]{5}{*}{ Total } & $\mathrm{N}$ & 40 & 40 & 40 & 40 & 40 & 200 \\
\hline & Média & 148,4 & 153,55 & 152,14 & 148,91 & 155,05 & 151,61 \\
\hline & Desvio-padrão & 23,91 & 18,96 & 20,38 & 21,62 & 24,09 & 21,82 \\
\hline & Mínimo & 90,38 & 91,76 & 104,27 & 92,79 & 84,64 & 84,64 \\
\hline & Máximo & 197,54 & 194,25 & 191,06 & 202,48 & 198,94 & 202,48 \\
\hline
\end{tabular}

\section{Tabela 4 Resultado das comparaçōes múltiplas para o tempo de fixação}

Comparação (horas)

$6 \times 12$
$6 \times 18$
$6 \times 24$
$6 \times 48$
$12 \times 18$
$12 \times 24$
$12 \times 48$
$18 \times 24$
$18 \times 48$
$24 \times 48$

Método de Bonferroni

$$
\begin{gathered}
p \text { (valor) } \\
>0,999 \\
>0,999 \\
<0,001^{*} \\
0,403 \\
>0,999 \\
<0,001^{*} \\
0,709 \\
<0,001^{*} \\
>0,999 \\
0,032^{*}
\end{gathered}
$$

*Estatisticamente significante. 
Tabela 5 Positividade segundo tempo de fixação e método de resgate

\begin{tabular}{|c|c|c|c|c|c|c|c|}
\hline \multirow{2}{*}{ Método de resgate } & & \multicolumn{6}{|c|}{ Tempo de fixação } \\
\hline & & 6 horas & 12 horas & 18 horas & 24 horas & 48 horas & Total \\
\hline \multirow[t]{5}{*}{ Microondas } & $\mathrm{N}$ & 10 & 10 & 10 & 10 & 10 & 50 \\
\hline & Média & 64,53 & 63,93 & 58 & 53,82 & 64,48 & 60,95 \\
\hline & Desvio-padrão & 14,9 & 5,82 & 15,45 & 18,62 & 16,7 & 15 \\
\hline & Mínimo & 38 & 52,17 & 35,06 & 28,25 & 28,57 & 28,25 \\
\hline & Máximo & 90,2 & 72,25 & 82,61 & 78,33 & 86,27 & 90,2 \\
\hline \multirow[t]{5}{*}{ Panela de pressão } & $\mathrm{N}$ & 10 & 10 & 10 & 10 & 10 & 50 \\
\hline & Média & 66,76 & 65,71 & 61,96 & 49,7 & 66,94 & 62,21 \\
\hline & Desvio-padrão & 5,9 & 12,32 & 9,85 & 14,31 & 11,95 & 12,62 \\
\hline & Mínimo & 61,09 & 44,22 & 45,54 & 31,67 & 45,71 & 31,67 \\
\hline & Máximo & 79,62 & 82,58 & 74,55 & 71,71 & 82,61 & 82,61 \\
\hline \multirow[t]{5}{*}{ Banho-maria } & $\mathrm{N}$ & 10 & 10 & 10 & 10 & 10 & 50 \\
\hline & Média & 59,84 & 58,01 & 55,15 & 46,76 & 40,42 & 52,04 \\
\hline & Desvio-padrão & 17,46 & 12,31 & 20,12 & 14,75 & 18,18 & 17,71 \\
\hline & Minimo & 22,53 & 31,84 & 25,87 & 23,73 & 19,62 & 19,62 \\
\hline & Máximo & 78,19 & 75,38 & 88,83 & 67,92 & 68,25 & 88,83 \\
\hline \multirow[t]{5}{*}{ Total } & $\mathrm{N}$ & 40 & 40 & 40 & 40 & 40 & 200 \\
\hline & Média & 66,08 & 65,24 & 63,64 & 49 & 59,1 & 60,61 \\
\hline & Desvio-padrão & 13,86 & 11,17 & 16,41 & 19,72 & 18,84 & 17,33 \\
\hline & Mínimo & 22,53 & 31,84 & 25,87 & 0,53 & 19,62 & 0,53 \\
\hline & Máximo & 90,2 & 85,1 & 88,83 & 87,14 & 86,77 & 90,2 \\
\hline
\end{tabular}

\section{Tabela 6 Resultado das comparaçōes múltiplas para o método de resgate}

\section{Comparação}

Microondas $\mathrm{x}$ p. pressão

Microondas $x$ banho-maria

P. pressão $\mathrm{x}$ banho-maria
Método de Bonferroni

$$
p \text { (valor) }
$$

0,999

$0,022^{*}$

$0,006^{*}$

*Estatisticamente significante.

\section{Referências}

I. CHEW et al. Microwave enhanced immunohistochemical staining of a formalin sensitive antigen laminin receptor. Anticancer Res, v. I6, n. I, p. 353-7, 1996.

2. COONS, A. H. et al. Immunological properties of antibody conteing a fluorescent group. Proceedings of the Society of Experimental Biology, v. 47, p. 200, 1941.
3. COSTA, M.Z. O. Histogênese da doença renal cística adquirida. Estudo imuno-histoquímico. 2003. Tese (mestrado) - Universidade Federal de São Paulo, Escola Paulista de Medicina, São Paulo.

4.CUEVAS et al. Microwave antigen retrieval in immunohistochemistry: a study of 80 antibodies. Journal Clin Pathol, v. 47, n. 5, p. 44852, 1994. 
5. ENGELMAN, M. F. B. et al. Estudo morfométrico do fígado de ratos submetidos a doses suprafisiológicas de tiroxina. Arquivos Brasileiros de Endocrinologia \& Metabiologia, v. 4, n. 2, 2001.

6. FROST, A. R. et al. Methods of antigen recovery vary in their usefullness in ummasking specific antigens in immunohistochemistry. Applied Immunohistochem Mol Morphol, v. 8, n. 3, p. 336-43, 2000.

7. GELB, A. et al. Estimation of tumor growth fractions in archival formalin fixed paraffin embedded tissues using two antiPCNA/cyclin monoclonal antibodies. Am J Pathol, v. I4I, p. | 453-8, 1992.

8. HAERSLEV,T.et al. Microwave processing for immunohistochemical demonstration of proliferating nuclear antigen (PCNA) in formalin fixed and paraffin embedded tissue. APMIS, v. 25, n. 10, p. I 107-9, 1988.

9. HALL et al. Proliferating cell nuclear antigen (PCNA) immunolocalization in paraffin sections: an index of cell proliferation with evidence of deregulated expression in some neoplasms. Journal of Pathology, n. 162, p. 285-94, 1990.

10. IMAN, A. S. et al. Comparison of two microwave based antigen retrieval solutions unmasking epitopes in formalin fixed tissue for immunostaining. Anticancer Res, v. 15, n. 4, p. I 153-8, 1995.

I ।. KOHLER, G. et al. Continuous cultures of fused cells secreting antibody of predefined origin. Nature, v. 25, p. 495-7, 1975.

12. KWASPEN et al. Periodic acidic as nonenzimatic enhancement technique for the detection of cytokeratin imunoreactivity in routinely processed carcinomas. Applied Immunohistochemistry, v. 3, n. I, p. 54-63, 1995.

13. LEONG; ANTHONY, S.Y. Applied immunohistochemistry for the sirurgical pathologist. Boston: Edward Arnold, 1993. p. 18.

14. MC CARTY, K. S. Jr. et al. $\bigcirc$ estrogen receptor analyses. Correlation of biochemical and immunohistochemical methods using monoclonal antireceptor antibodies. Archives of Pathology and Laboratory Medicine, v. 109, p. 716-21, 1985.

15. MILLER, R. T. et al. Fixation and epitope retrieval in diagnostic immunohistochemistry: a concise review with practical considerations. Applied Immunohistochemistry \& Molecular Morphology, v. 8, n. 3, p. 228-35, 2000.

16. NAKANE, P.K. et al. Enzime labelled antibodies: a preparation for the localization of antigen. Journal of Immunohistochemistry and Cytochemistry, v. 14, p. 929-31, 1966.

17.Papolla, M. R. Computadorized image analyses microespectroscopy of tissue sections. Archives of Pathology and Laboratory Medicine, v. I 12, p. 787-90, 1988.
18. PORTIANSKLY, E. L. et al. Kinects of epitope retrieval techniques for unmasking citokeratins in bovine prostatic tissues after different formaldehyde fixation times. Applied Immunohistochemistry, v. 5, n. 3, p. 194-201, 1997.

19. SARNAT, $H$. B. et al. Synatophisyn immunocitochemistry with termal intensification: A marker of terminal axonal maturation in the human fetal nervous system. Brain Dev, v. 2I, n. I, p. 4I-50, 1999.

20.SHI,S. R. et al.Antigen retrieval in formalin fixed, paraffin embedded tissues: an enhancement method for immunohistochemical staining based on microwave heating of tissues sections. J Histochem Cytochem, v. 39, p. 74I-8, 1991.

21. SHI, S. R. et al. Antigen retrieval technique: a novel approach to immunohistochemistry on routinely processed tissue sections. Cell Vision, v. 2, p. 7-22, 1995.

22. SHI, S. R. et al. Standarzitation of immunohistochemistry based on antigen retrieval technique for routine formalin fixed tissue sections. Appl Immunohistochem, v. 6, p. 89-96, 1998.

23. STERBERG, L. A. et al. The unlabed antibody enzyme method of immunohistochemistry. Preparation and properties of soluble antigen complex (horsehadish peroxidase-antiperoxidase) and its use in the identification of spirochets. Journal of Histochemistry and Cytochemistry, v. 30, p. 315, 1970.

24. SUURMAJER, A. J. H. et al. Pretreatment in hight pressure microwave processor for MIB I immunohistaining of cytological smear and paraffin tissue sections to visualize the various phases of the mitotic cycle. The Journal of Histochemistry, v. 47, n. 8, p. 1015-20, 1999.

25. Taylor, C. R. et al. Strategies for improving the immunohistochemical staining of various intranuclear prognostic markers in formalin paraffin sections: androgen receptor, estrogen receptor, progesterone receptor, P53 protein, proliferating cell nuclear antigen and Ki67 antigen revealed by antigen retrieval techniques. Coment in Human Pathol, v. 25, n. 10, p. I|07-91, 1994.

26. THEREZO, A. L. S. et al. Histogenesis of the cysts in the autossomal dominant. Polycitic kidney disease: am immunohistochemical study. Applied Immunohistochem, v. 6, p. 219-33, 1998.

27. TOGNINI, F. J. R. Estudo biomecânico da cicatrização da parede abdominal de ratos sob a ação de Meloxicam. 1999. Tese (doutorado) - Universidade Federal de São Paulo, Escola Paulista de Medicina, São Paulo.

28. VON WASIELEWISKI, R. et al. Effects of antigen retrieval by microeave heating in formalin fixed tissue sections on a broad panel antibodies. Histochemistry, v. 2, n. 3, p. 165-72, 1994.
Endereço para correspondência Leonor Cristina Manoja Roman Rua Cardoso de Almeida 1.257/53 - Perdizes CEP 05013-001 - São Paulo-SP e-mail: avmmartinez@aol.com 